\title{
The Teaching, the Research and the University Extension and Educational Demands: Historical Challenges for Initial and Continued Teacher Formation
}

\author{
Rosane Michelli de Castro', Vandeí Pinto da Silva1, Maria Silvia Rosa Santana², \\ Joice Ribeiro Machado da Silva ${ }^{3}$ \\ ${ }^{1}$ Department of Didactics and Program of Postgraduate on Education, Faculty of Philosophy and Sciences, \\ University Estadual Paulista "Julio de Mesquita Filho" - UNESP/Marília, São Paulo, Brazil \\ ${ }^{2}$ Pedagogy and Social Sciences Courses and Program of Postgraduate on Education, State University of Mato \\ Grosso do Sul, Paranaíba, Brazil \\ ${ }^{3}$ School of the Basic Education, Federal University of Uberlândia, Minas Gerais, Brazil \\ Email: rosanemichelli@marilia.unesp.br, vandeips@uol.com.br, mariasilvia@uems.br, joice.rbr@gmail.com
}

Received 31 May 2016; accepted 11 July 2016; published 14 July 2016

Copyright (C) 2016 by authors and Scientific Research Publishing Inc.

This work is licensed under the Creative Commons Attribution International License (CC BY).

http://creativecommons.org/licenses/by/4.0/

(c) (i) Open Access

\section{Abstract}

This article has a main goal to present results of the reflection on some aspects of historical challenges for initial and continuing teacher formation in Brazil. Our reflections have been prepared and envisaged in our defenses in processes that must happen under solid offered foundations, centrally, in direct relation to university contexts signed on the tripod teaching, research and extension. However, we consider that the legal aspects that have guided the formation process of teachers in Brazil have favored both the theoretical emptying of these processes, as certain strangeness, by teachers of their own teaching. We believe in the end that the formation process of teachers in Brazil, in a direct relationship with the teaching, research and university extension, should provide training and work conditions so that teachers can take as posture and as conception of the world the search for radical (root) apprehension of the educational phenomenon in its essence, beyond what it is immediately noticeable, in an unveiling effort of the laws that produced such phenomenon.

\section{Keywords}

Education, Teacher, Teaching, Research, Extension 


\section{Introduction}

The initial and continuing teacher formation in Brazil has undergone significant changes over the past 50 years. It was only after the mid-twentieth century, in Brazil, that investments for the universalization of then primary education were intensified. From an economic point of view, the country should overcome the condition of producer and exporter of agricultural products and invest in its own industry and commerce. With that, school education should be generalized in order to adapt workers to new market demands.

The creation of more schools to alphabetize all Brazilians in the first four years of schooling had generated great demand for teacher formation. Normal schools, aimed at training of primary teachers, are the ones that undertaken this role. This training was given at the secondary level, particularly through the magisterium courses and had its improvement in the Specific Center of Formation and Improvement of the Magisterium (CEFAM), which was intended to replace the old magisteria and normal schools for a better qualified formation model, scheduled for 4 years, full-time and scholarships offered to students.

Teacher formation to work in the elementary school (5th to 8th grades) and high school (1st to 3rd years of secondary) required higher education.

With the Law of Guidelines and Bases of National Education-LDB n. 9394/96, the teacher formation in Brazil had a quantitative expansion. Under Article 62 of the law, amended by law 12.796/2013 (Brazil, 2013), the formation of all teachers should be given at a higher level. This legal requirement brought as a side effect the closing of good training schools for magisterium and the indiscriminate creation of Normal Superior Courses and Pedagogy courses, with questionable qualifications, many of them as complementation of magisterium training and with distance learning $(\mathrm{EaD})$ resources.

Currently, the initial formation of teachers to work in Early Childhood Education and Initial Years of Elementary School occurs mainly in Pedagogy courses and in some Superior Normal courses. The discussions on the Pedagogical Political Project of Pedagogycourses and its identity have been quite tense because their responsibilities to form the teacher to work in Early Childhood Education (nursery and pre-school), in Elementary School (1st to 5th years), the School Coordination and Management and also in programs such as the Youth and Adult Education, Indigenous Education and Education of Students with Special Educational Needs. In the case of Superior Normal Courses, the most scathing critique lies on the precarious theoretical formation offered by them and their inability to articulate the teaching, research and extension.

In Brazilian education, the historical need to form more teachers, the poor formation offered to them and the challenges posed to their work are factors that requested continuing education. In this context, it has been implemented a model of compensatory continuing formation, which is more focused on the recovery of the needs of initial formation then the required update and enrichment of the teacher's formation. Regarding the continuing education of teachers in Brazil, we believe and have advocated the effective supply of teachers' working conditions and that the continuing formation is given, priority, in schools where teachers work and consider their work context. We understand that the initial training and continuing education of teachers in Brazil should take place under a solid foundation offered, centrally, in direct relation to university contexts signed on the tripod teaching, research and extension and thus articulated to the context of schools where teachers act. It is under this perspective that, in this article, we present some reflections.

\section{Some Aspects for the Historical Confrontation of Teacher Formation in Brazil ${ }^{1}$}

The Brazilian socio-economic-political context of the 1960s, whose idea of instrumental rationality was imposed as something hegemonic, had imposed for higher education institutions the responability for producing and "theorizing" the means that would allow to conceive, coordinate and enable more efficient and productive actions, which should have as goal, at least to have some political rhetoric effect, the promotion of a society resulting from greater participation and social welfare. That is, such actions should turn to the creation of conditions which, at least apparently, would mean the modernization of the country, defended in economic terms by the speech to overcoming the economic dependence from countries considered as developed, and, politically, by speech to overcome the "[...] clientelistic, corporate, oligarchic and authoritarian models [...]" (Dias, 1989: p. 27), predominant in Brazil so far.

According Zainko (1998: p. 40), the modernization speeches in Brazil, once established in the idea of disruption of economic dependence, brought to higher education institutions responsible for producing the technical

${ }^{1}$ Text prepared from Castro (2009). 
and technologies necessary for the autonomous development of the country. Then, it was responsability of higher education institutions to devote themself to the technique of production, of the "[...] know how to do with wide scientific basis” (Zainko, 1998: p. 27), fact by which had occurred during the 1960's, “[...] a considerable increase in the number of people dedicated to research activities [...]” (Biojone, 2001: p. 14).

For the discursive materialization of ideas that attached the modernization of the country to the production of this "[...] know how to do with wide scientific basis", the authoritarian government, established in Brazil after the 1964's Military Coup, established a Working Group to preparing a reform of the Brazilian university system “[...] with a clear influence of American consultants who participated in the country's modernization process.” (Zainko, 1998: p. 47).

"By its very heterogeneous composition, the Working Group presents in its report on the University Reform a University conception that combines a double point of view; the idealistic, in which the University is defined as "a masterpiece of the spirit"; "expression of the creative and critical rationality"; and the technicalities that defines it "as one of the essential factors in the development process: a pre-investment in the rational process of building the new society through global and qualitative transformation of its structures, aiming to promote the man in the fullness of its dimensions.” (Zainko, 1998: p. 47).

Times were passed when there was defense of the higher education idea, mainly in which it was expected to constitute in the universities, responsible for the integration of production, transmission and specialization of knowledge, the latter linked to the enlargement of the human mind, the creation of a nationalist culture (Zainko, 1998).

Newton Sucupira, a member of the Working Group for the preparation of the proposal for such a reform, constituted by the military government of the 1960s, even considering that intellectual production should not measure itself by strictly economic criteria, had said that universities, and, perchance, some isolated school of higher education, ${ }^{2}$ should be constituted in the form of knowledge to be defined in terms of service and practice efficiency, not being able to scape the need for rationalization, for him, one of the characteristics of industrial societies. (Sucupira apud Zainko, 1998: p. 48).

Knowledge defined in terms of service and practice efficiency with streamlined resources: all this should materialize in educational institutions responsible for the formulation of human knowledge to be taught especially in universities which should be transformed into "research schools", "research universities", which, according Zainko (1998: p. 32), earned more clearly shape when discussed in terms of base universities devoted to postgraduate.

According to the opinion of leading educators of the time, including Anísio Teixeira, it would not be any higher education institution in Brazil deserving of this important mission, because, for him, “[...] only the most structured universities, and in conditions to attract an important framework of teachers/researchers, would be able to be research Universities.” (Zainko, 1998: p. 33).

The proposals and the final text of university reform were invaded by the speeches of the necessary inseparability of teaching and research, articulated to the rationalization of resources, in pursuit of greater efficiency and productivity, to the improvement of the critment processes and maintenance of teachers and to the quality of management of the means to be employed.

In the administrative structure of the establishments responsible for this level of education (Cunha, 1989: p. 26), the organizational principles of strict control and supervision of resources prevailed, from which many of the processes of constitution of the intellectuals' senses of practices in these establishments have been forged, however, justified by educational policy control and centralization of decisions by the government, being the most representative of them, at the time, led to the interior of higher education institutions with the enactment of Law no. 5,540/68, from the University Reform, replacing the chair system by the department.

According to paragraph 3 of Art. 12 of this Law, the department would be "[...] the smallest fraction of the University structure for all purposes of administrative, didactic and scientific organization and personnel distribution, and [comprehend] related disciplines.” (Brazil, 1968: p. 1435).

In the opinion of Brazilian educators, among them Florestan Fernandes (1962), this new structure would encourage the achievement of the central objectives that were aimed at higher education institutions, especially the Faculties of Philosophy, in that, with the rationalization of its functioning, it would had lowered its cost, simplifyed its organization, it would increase its effective performance, in way to form different types of intellectuals, able to perform activities in both the teaching and the research sector. 
The teaching-research inseparability, so discussed and recommended in the letter of the Law of University Reform of 1968, assumed, indispensably, scientific production.

Given these contextual peculiarities, Teixeira, like many others who had spoken out about the process and the product of the 1968's University Reform, said that this was a period in which "[...] despite the tradition, the superior education existing sought the passage of a literary culture to a scientific culture [...]" (Zainko, 1998: p. 49), which would imply: [...] "Mentality and attitudes changes, acceptance of the scientific method, trial practice in the field of pure and applied science, and lucid and healthy professional relationship, based on high standards of competence and scientific honesty." (Cunha, 1988: p. 309).

Even considering the strong military controller action period in Brazil at the time, the moment would have required the creation of spaces within universities and isolated faculties that intellectuals could, even under strong control scheme and ordination, add to the required rationality the ingredients of creation and criticism, peculiar to the activity developed by them.

Gradually, a framework had been outlined, for compliance with the requirement, in schools of higher education. In the first instance, there would be to think about the strategy or means to be admitted by the set of intellectuals of such institutions, which would be responsible for the legitimacy of the researchers and the knowledge they communicated.

The idea of production of information, its inclusion in the communication channels recognized by the scientific community, and ultimately the legitimacy of this information as knowledge by researchers and intellectuals of the academies was gradually incorporated by intellectual groups of higher education institutions, as an activity necessary for its maintenance.

However, knowledge then produced by the university, once this one standing and existing within a society, it would only make sense if it would extrapolate the walls of the University and would meet the demands of this society that had designed and maintains it. Thus, the triple bottom university arises: the teaching, research and extension.

The projects and extension activities have gained gradually space in teaching activities and also gradually the university for excellence started to condition its existence also to this extensional base.

But the projects developed with such nature are increasingly being designed to meet the real social, educational and market demands, not just as an argument and objective of disinterested character research.

In this sense, following the conception of production in the capitalist way, the production of knowledge in higher education has been linked increasingly to a pragmatic and utilitarian character, in which some areas of knowledge, just as they allow the material production, are highlighted in the national and international scenario. As a result, we have these areas, especially the Exacts and Biomedical, most valuable with financial resources for their research, resources which not always come from public sources; but, once they receive private funds, they follow the prevailing interests of those who finance them.

In this scenario, the Humanities lose academic space and social strength, since their ultimate goal is to reflect on the society in its complexity, seeking to uncover the bowels full of diverse meanings and interests, to bring to consciousness the forms of social action and its consequences for the community. Their demand, thus, runs (or should run) the market logic, staying on the sidelines of what we conceive today as higher education.

The licentiate degrees, privileged space in higher education for initial teacher formation, reflect well this reality. According to data from the Higher Education Census, released by INEP (National Institute of Educational Studies Anísio Teixeira):

"Of the enrollments in licentiate degree courses registered in 2014, 41.2\% are in public institutions and $58.8 \%$ are in private Higher Education Institution;

-The number of enrollments in colleges in undergraduate courses is $19.6 \%$ of total enrollment in this academic degree;

-More than half of enrollment in undergraduate courses in private schools is offered by distance (51.1\%). In public, this figure is 16.6\%.” (Brazil, 2014: p. 8).

The fact that the majority of university formation of future teachers is linked to courses offered by private colleges focuses directly on a primary feature of this formation: it is almost exclusively linked to education, little (or no) space left for research or for extension. This feature reinforces the pragmatic and utilitarian character of such formation. 
Other data provided by the Higher Education Census can reinforce the questioning in relation to teacher training: "The enrollment of distance courses are predominant in the private institution and licentiate degree courses.” (Brazil, 2014: p. 7), and featuring the students of Distance Learning: "The typical student of undergraduate distance learning courses is in the licentiate degree. In presential mode, the student attends bachelor.” (Brazil, 2014: p. 4).

The spread of the number of licentiate degrees and Normal Superior courses in recent decades, especially in the private sector, as pointed out in this article, is due to the demand brought by LDB 9394/96. This law is the result of an intense process of debate among Brazilian educators and political class, which did not contemplate what educators wanted as "quality education", aiming to expand quantitatively and mainly qualitatively the access to education for the Brazilian population.

As a signatory of the World Conference on Education for All, held in Jomtien (Thailand) in 1990, which guided the approval of LDB 9394/96, was the fact that the Brazilian public policies for education started to be prepared based on the principles defended in this Conference, aiming to seek a quality basic education for children, youth and adults.

"Brazil, such policies greatly influenced the political and ideological bases that supported the official documents since the publication of the Ten-Year Plan for Education for All in 1993, in the government of Itamar Franco (1992-1995), a trend that has already visualized from the MEC-USAID agreements signed during the military dictatorship and, on a different scale, obtained strength under the Collor government (1990-1992), with his country’s integration program in the world market.” (Santana, 2013: p. 49)

The law 9394/96, followed by the drafting of the National Curriculum Standards in 1998, are shown as means of realization of the precepts conveyed by neoliberal logic in education: "With this plan, Brazil drew local goals from the agreement signed in Jomtien and waved to multilateral organizations that the educational project they prescribed would be here deployed” (Shiroma, Moraes, \& Evangelist, 2004: p. 62).

Backed by a foreign policy that began with the MEC/USAID agreements, and found fertile soil in the internal and external political, the educational ideal was being outlined by the marketing neoliberal logic.

"With this commitment assumed, the countries with the highest illiteracy rates had to trigger actions that consolidate the principles elaborated in that Declaration, including Brazil. Therefore, these countries had to resort to external funding, submitting to the determinations of the International Financial Institutions (IFIs), particularly the International Monetary Fund (IMF), which operates in a general economic context, and the World Bank (WB), that working cooperatively with the IMF, eventually seek in education the conditions for the development of its economic policy.” (Santana, 2013: p. 46).

Focusing on preparing the new generations for new market challenges of the twenty-first century, such international organizations focused its determinations in basic education, on the grounds that such educational level covers most of the population. In justifying the reasons for the emphasis on basic education, the World Bank is categorical:

“The Bank’s response is clear: education, especially primary and secondary (basic education), helps reduce poverty by increasing poor's labor productivity, reducing fertility, improving health, and endows people with attitudes they need to fully participate in the economy and in society.” (Shiroma, Moraes, \& Evangelist, 2004: pp. 74-75, emphasis of the authors).

In the formation of a collective consciousness about the direction of education, Gentili (1998: p. 19) states:

"It is, in short, to transfer the education from policy sphere for market sphere, denying its status as a social right and turning it into a possibility of individual consumption, variable according to merit and the ability of consumers. Education should be thought of as a good subject to differential rules of competition. Far from being a right enjoyed by all citizens, transparently it should be established as an opportunity that is presented to individuals entrepreneurs, the "responsible" consumers, the sphere of a flexible and dynamic market (the school market).”

To that end so well delineated, public policies, strictly linked to external determinations because they are linked to the release of funds, outline the new curricular designs of teacher formation, which must meet the appropriate profile. 
According to (Shiroma, Moraes and Evangelist, 2004: pp. 68-69, the authors' emphasis), the Delors Report clearly shows this profile:

"The teacher, taken as a change agent, is responsible for the realization of the ideals of the XXI century. Its main characteristics would be competence, professionalism, devotion. But it is supposed to have other teaching skills such as empathy, authority, patience and humility. An edifying teacher, anyway. [...] The Delors Report points out that in addition to teaching skills, it will be required from the teacher a formation for research. It demands a higher education for all professionals, not necessarily University, advocating an initial formation with ties between universities and formation institutes. Another strong idea appears in this case. The report recommends that the teacher pursues other professions than their own, of being a teacher. The goal, it is argued, is to establish greater mobility between jobs, which would favor the expansion of its vision of reality.”

Faced with this quote, it behooves us to ask, which change the Report refers, when it promotes the teacher as an agent in charge? What conception of research runs, since it advocates a formation not necessarily from University, while maintaining the link between universities and training institutes? What role would play the theoretical and pedagogical knowledge for teaching practice in what the report calls "pedagogical skills"?

Disregarding such knowledge as basic of the teaching profession, teacher education, compared to international documents, entered an emptying process of theoretical contents and strengthening the technical model of professional training, much more focused on the "how to do" than the "why to do", "for to", "when to do" and "for whom to do", since the latter doings require knowledge beyond educational practices.

"This is an example of the materialization of one of the mechanisms by which gives the estrangement phenomenon of work (Marx, 2009) [...]. Through it, it is developed the feeling of disbelief in the knowledge of the teacher, in a clear intention of weakening any possibility of creating a collective thinking environment on the lived reality and on the concepts that form from it, of any possibility of construction, in fact, a collective work for the community served by that particular school.” (Santana, 2013: p. 54)

By following, even after several changes in the Curriculum Guidelines for teacher formation courses, the above determinations, yet in a disguised way in the arrangements of the educational projects of these courses, what we have is an initial formation that cannot work with theoretical and practical contents aiming the establishment of a teacher who, besides having specific knowledge of his area, understands the human development process, how occurs the process of learning and how the teaching process needs to be organized in order to enhance learning, fulfilling goals to effectively develop the thinking and ways of understanding the world and student expression.

The most frequent reason for this insufficient formation is that the teacher needs to study throughout his career and that supplementation of knowledge is possible with continuing education, or service. However, how it's possible to expect that the teacher, already immersed in the world of school work, alienated labor as it is typical in the capitalist society mode, which preparation was limited to the pragmatic models, to be interest in formation that goes beyond the everyday understanding of school problems and instrumentalizes it for a different approach?

These social and educational demands within the school, so in education, need to be developed effectively by teachers in service, in a different conception of continued formation in the schools where they work.

Meanwhile, the responsible at the level of the educational system, as many of the professionals who are ahead of the Municipal Departments of Brazilian Education, seek to invest efforts to make this differentiated training happens in public schools. But everything has taken too long for us to visualize significant changes. It is a laborious work! Even because it is a small percentage of teachers who, being wrapped in the process of "estrangement of his work", as mentioned by Marx (Santana, 2013: p. 14), has not been able to have interest in the courses offered in teacher's continued formation.

\section{Continued Formation Processes in Brazilian Education Systems}

Given the historical complexity of teacher formation processes that we have mentioned before, it is in charge of education systems to think alternatives to motivate teachers to continue their formation. This role is not simple, it involves a dilemma that collides with another function that is also part of this system: the collection for best 
results. In this article, it will not be possible to look into the question of the search for results, because the focus would divert to issues of internal and external evaluations under which currently the Brazilian schools pass, and which subject we have discussed in Silva et al. (2015). The debate is about the current formation processes present in educational systems and that have two fronts, the first: about paid and working hours; and the second, organized by the responsible agencies and offered outside the working hours.

The processes of continuing education in Brazilian education official networks are officially supported by federal, state and local laws. These laws require that $1 / 3$ of the workload of teachers are dedicated to extracurricular activities, including there the continued education. We may consider these demands a breakthrough in terms of legislation regarding the working conditions of teachers, however, not all school systems follow this legal determination. In São Paulo, for example, a teacher who works in the early years of basic education and has a workload of 27 hours per week, will have 2 hours to formation times. These moments are called Pedagogical Collective Work Hours-HTPC and are led by coordinators of the schools that, a priori, should articulate the necessary demands that require deepening of studies of by the teachers in order to find answers to the own school's needs.

Even with this space studies guaranteed by law, implemented in all Brazilian states, there is not a significant advance in improving education. It happens that, not always, this space for formation is seen as important or necessary, and in many situations it is even twisted from its main function, the reflective study. To overcome this situation, it is required a lot of commitment of both the teachers and the management teams of each school. Rethinking the importance of the teacher's role is urgent, so that it can be possible to break this "strangeness of work" referred previously.

As a second perspective of continued education of the teacher, there is another possibility which setting is marked by moments outside of work hours. In this case, there is the aggravation of the participation of teachers, since in these occasions, they are invited to participate. And what we see working in different school systems or establishing partnerships, is that teachers who seek to deepen their theoretical concepts in order to improve their practice are always the same ones. And in that sense it can be concluded that the garantees of significant improvement of in the school system is compromised, since such training reaches only a small part of teachers.

However, still, it is clear the involvement of teachers who seek to broaden their knowledge because they want to change their practice. The formation process offered departs from an analysis that the school systems perform and according to the needs, proposing a specific training through short courses, to meet the real needs of teachers.

Another configuration, widely used in this type of training offered, is courses organized in the form of educational workshops. In this format, it is possible to begin from practical considerations and examine them in the light of the chosen theoretical framework. The teacher then is invited to experience new practices in their dynamics of the classroom, so to envision a better learning process of their students, to gradually transform and improve their way of teaching. In this sense, the educational workshops offered should consider the knowledge brought by the teachers and after the theoretical debates of other practical possibilities, the teachers would be invited to use it in order to include it in their actions. It is in practice and for practice that the theoretical concepts are taking shape, reconfiguring and showing its validity.

\section{Brief Closing Remarks}

Finally, the formation process of teachers in Brazil is considered in a direct relationship with the teaching, the research and the university extension, should provide conditions for formation and work so that teachers could take as posture, as conception of the world, search the radical (root) seizure of the educational phenomenon in its essence, beyond what is immediately noticeable to us, in an unveiling effort of the laws that produced such a phenomenon.

Such processes, if conducted, would produce results, from our point of view, in favor of the effective development of educational demands, especially by teachers in service in schools, demands that would allow even that the university could accomplish its purposes based on the tripod teaching/research/extension.

For this, it is necessary to break, as Gramsci says (Frigotto, 2006: p. 77), with the alienating logic imposed on the institutions of our social system and, in particular, in our public school focused on teacher education, and seek to promote conditions for formation in service for the promotion of thinking critically and of the research, based on different conceptions of reality gestated in the cultural and historical world, therefore concrete. 
This has been the basis of our defenses to overcome the challenge of teacher education in Brazil, mainly against the precarious conditions of work and formation to them imposed historically in Brazil, which favor the alienating conditions.

\section{References}

Biojone, M. R. (2001). Form and Function of Scientific Journals in Science Communication. São Paulo: Dissertation (Masters in Information and Documentation Sciences), ECA/USP.

Brazil. (1968). Law n. 5540 of 28 November 1968. Fixed Rules of Organization and Functioning of Higher Education and Its Articulation with the Middle School, and Other Measures (pp. 1433-1440). Lex: Federal Legislation.

Brazil. (2013). Ministry of Education. Law No. 9394 of 20 December 1996. http://www.planalto.gov.br/ccivil_03/_Ato2011-2014/2013/Lei/L12796.htm\#art1

Brazil. (2014). Ministry of Education. National Institute of Educational Studies Teixeira (INEP). Notes on Higher Education Census 2014.

http://download.inep.gov.br/educacao_superior/censo_superior/documentos/2015/notas_sobre_o_censo_da_educacao_sup erior_2014.pdf

Castro, R. M. (2009). The Production of a College: The Alfa Magazines, Historical and Didactic Studies and FAFI Marilia (1959-1975). São Paulo: Academic Culture; Marilia: Fundepe 2009.

Cunha, L. A. (1988). The Reformed University: The 1964 Coup and the Modernization of Higher Education. Rio de Janeiro: Francisco Alves Bookstore Publishing House.

Cunha, L. A. (1989). Which University? São Paulo: Cortez.

Frigotto, G. (2006). The Focus of the Historical Materialist Dialectics in Educational Research. In I. Farm (Ed.), Methodology of Educational Research (10. ed., pp. 69-90). São Paulo: Cortez.

Gentili, P. (1998). Falsification of Consensus: Simulacrum and Imposition of Neoliberalism in Education Reform. Petrópolis, RJ: Voices.

Santana, M. S. R. (2013). Teaching Work and Questioning the Pedagogical Practice in the Light of the Historical-Cultural Theory. Marilia, SP: Thesis (Doctorate in Education)_FFC/UNESP Marilia.

Shiroma, E. O., Moraes, M. C. M., \& Evangelista, O. (2004). Educational Politics (3. ed.). Rio de Janeiro: DP \& A.

Silva, V. P., Silva, J. A. M., \& Castro, R. M. (2015). Interdisciplinary Formation and Social Integration in Present-Day. Creative Education, 6. http://dx.doi.org/10.4236/ce.2015.617186

\section{Submit or recommend next manuscript to SCIRP and we will provide best service for you:}

Accepting pre-submission inquiries through Email, Facebook, Linkedin, Twitter, etc

A wide selection of journals (inclusive of 9 subjects, more than 200 journals)

Providing a 24-hour high-quality service

User-friendly online submission system

Fair and swift peer-review system

Efficient typesetting and proofreading procedure

Display of the result of downloads and visits, as well as the number of cited articles

Maximum dissemination of your research work

Submit your manuscript at: http://papersubmission.scirp.org/ 